Even with robots now appearing, surgeons should not give free rein to their Luddite tendencies. Technological advances have always made easier what was once difficult. The same advances make the previously impossible merely the very difficult. The challenge of surgery, and the potential for progress, remains.

1 Leighton SEJ, Rowe-Jones JM, Knight JR, Moore-Gillon VL. Day case adenoidectomy. Clin Otolaryngol 1993;18:215-9.

2 Earnshaw RA, Gigante MA, Jones H. Virtual reality systems. Academic Press, 1993:327.

3 Zorowka PG. Otoacoustic emissions: a new method to diagnose hearing impairment in children [review]. Eur F Paediat 1993;152:626-34.

4 Owens JJ, McCoy MJ, Lonsbury-Martin BL, Martin GK. Otoacoustic emissions in children with normal ears, middle ear dysfunction, and
ems emissions in children with normal ears,

5 Norton SJ. Application of transient evoked otoacoustic emissions to paediatric populations [review]. Ear and Hearing 1993;14:64-73.

6 Anholt RR. Molecular neurobiology of olfaction. Crit Rev Neurobiol 1993;7: $1-22$

7 Coticchia JM, Fredrickson JM, el-Mofty S, Miller DA. Effect of KTP laser ablation of endochondral bone on bone healing. Am $\mathcal{F}$ Otol 1993;14:230-7.

8 Korff M, Bent SW, Havig MT, Schwaber MK, Ossoff RH, Zealear DL. An investigation of the potential for laser nerve welding. Otolaryngol Head Neck Surg 1992;106:345-50.

9 Herdman RCD, Charlton A, Hinton AE, Freemont AJ. An in vitro comparison of the Erbium: YAG laser and the carbon dioxide laser in laryngeal surgery. F Laryngol Otol 1993;107:908-11.

10 Hagen R. TVoice rehabilitation following total laryngectomy: microvascular laryngeal replacement-plasty (laryngoplasty) instead of voice prosthesis.] Laryngorhinootologie 1990;69:213-6. (In German.)

11 Green DC, Berke GS, Graves MC, Natividad M. Physiologic motion afte vocion after vocal Cord Beine Croft CB, Golding-Wood D. Uses and complications of uvulopalatopharyngoplasty. F Laryngol Otol 1990;104:871-5.

3 Ellis PD, Williams JE, Shneerson JM. Surgical relief of snoring due to palatal flutter: a preliminary report. Ann R Coll Surgeons Engl 1993;75:286-90.

14 Lund VJ, MacKay IS. Outcome assessment of endoscopic sinus surgery. $f$ Soc Med 1994;87:70-2.

15 Kaluskar SK, Patil NP, Sharkey AN. The role of CT in functional endoscopic sinus surgery. Rhinology 1993;31:49-52.

16 Goode R. Implantable hearing devices [review.] Med Clin North Am 1991;75 1261-6.

17 McGee TM, Kartush JM, Heide JC, Bojrab DI, Clemis JD, Kulick KC Electromagnetic semi-implantable hearing device: phase I. Clinical trials. Laryngoscope 1991;101:355-60.

18 Proops DW. Bone anchored hearing aids and prostheses. $f$ Laryngol Otol 1993;107:99-100.

19 Jacobsson $M$, Albrektsson T, Tjellstrom A. Tissue-integrated implants in children. Int $f$ Paediat Otorhinolaryngol 1992;24:235-43.

20 Cohen NL, Waltzman SB, Fisher SG. A prospective randomised trial of cohen NL, Waltzman SB, Fisher SG. A prospection
cochlear implants. New Engl \% Med 1993;328:233-7.

21 Luetje CM, Whittaker CK, Geier L, Mediavilla SJ, Shallop JK. Feasibility of multichannel human cochlear nucleus stimulation. Laryngoscope 1992;102: 23-5.

22 Migueis A, Portmann M. [Bulbar auditory nuclei: morphological study, consequences for implantation of electrodes.] Rev Laryngol Otol Rhinol 1991;112:269-71. (In French.)

23 Cain P, Kazanzides P, Zuhars J, Mittelstadt B, Paul H. Safety consideration in a surgical robot. Biomed Sci Instrum 1993;29:291-4.

24 Koivukangas J, Louhisalmi Y, Alakuijala J, Oikarinen J. Ultrasoundcontrolled neuronavigator-guided brain surgery. I Neurosurg 1993;79: 36-42.

\title{
Controversies in Management
}

\section{Should obesity be treated?}

\section{Treatment is necessary}

\section{J S Garrow}

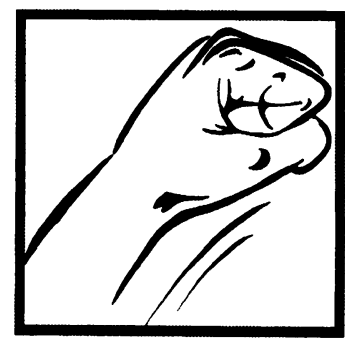

This is the second in a series of articles examining some of the difficult decisions that arise in medicine
Most people will agree that mending machinery which has broken, teaching a child useful skills, and preserving an artistic masterpiece are, in principle, useful. Most will also acknowledge that it is possible to do these tasks so badly that the final state is worse than at the start. Similarly, it is possible to treat obesity so incompetently that the net effect is to make the obese patient worse. We should not argue from this that we should not treat obesity, any more than that we should not mend machinery, teach children, or preserve artistic masterpieces. I will assume, therefore, that by treating obesity we mean doing so with reasonable competence. Two further definitions need stating. By "obese" I mean having a Quetelet's index (body mass index) over 30 . Also, I assume that the objective of all medical treatment is to make life more tolerable to patients by increasing the extent to which they can undertake activities or projects that they reasonably want to do.

\section{Adverse effects of obesity}

Disabilities associated with obesity are decreased longevity and increased risk of cardiovascular disease, hypertension, diabetes, osteoarthritis, and some forms of cancer sensitive to sex hormones. With weight loss longevity increases and the risk of these diseases falls.' Obese people are also discriminated against socially and tend to have a low self esteem. Psychologists may argue that by advocating weight loss we are condoning the discrimination against obese people and that when the treatment fails this will further damage the patient's self esteem. ${ }^{2}$ I think this argument is nonsense: patients' morale may improve in the short term when they are assured that they have a right to be obese, but this does not reduce the long term physical penalties listed above. Certainly it is unethical to make a half hearted attempt to treat severe obesity, since in this case the chance of achieving worthwhile weight loss is poor and the danger of damaging the patient's self esteem by failure is great.

There are two crucial questions in this debate. Firstly, is it physiologically possible for a severely obese patient to achieve normal weight and health? Secondly, if so, is the cure less distressing for the patient than the disease? Unless we can answer yes to both questions we should not treat obesity.

There is ample evidence to show that obese people can achieve normal weight. Under metabolic ward conditions any desired weight can be lost, at a rate of about $1 \mathrm{~kg} /$ week, by following a reduced energy diet. ${ }^{13}$ Statements that metabolic rate falls and blocks further weight $\operatorname{loss}^{2}$ are incompatible with the evidence. ${ }^{4}$ Whether the cure is more distressing than the disease is more difficult to answer, since it depends on the patient's perception of the efficacy of dieting and of the probable consequences of remaining obese. This perception is affected by propaganda that obesity is not really a health hazard, that dieting is physiologically doomed to failure, or that weight can easily be lost without dieting by means of some magic pill or potion. The more persuasively arguments are advanced that obesity cannot be treated, or should not be treated, the more difficult it becomes to treat.

\section{Who should treat obese patients, and how?}

The prevalence of obesity is rapidly increasing in many countries, including the United Kingdom (figure). ${ }^{5}$ I have already noted the dangers of inadequate treatment, so with limited NHS resources how can adequate treatment be provided for the $13 \%$ of adults who are obese?

It is impractical to suggest that doctors in hospital or general practice should see patients individually and follow them up adequately. I believe that a combined 

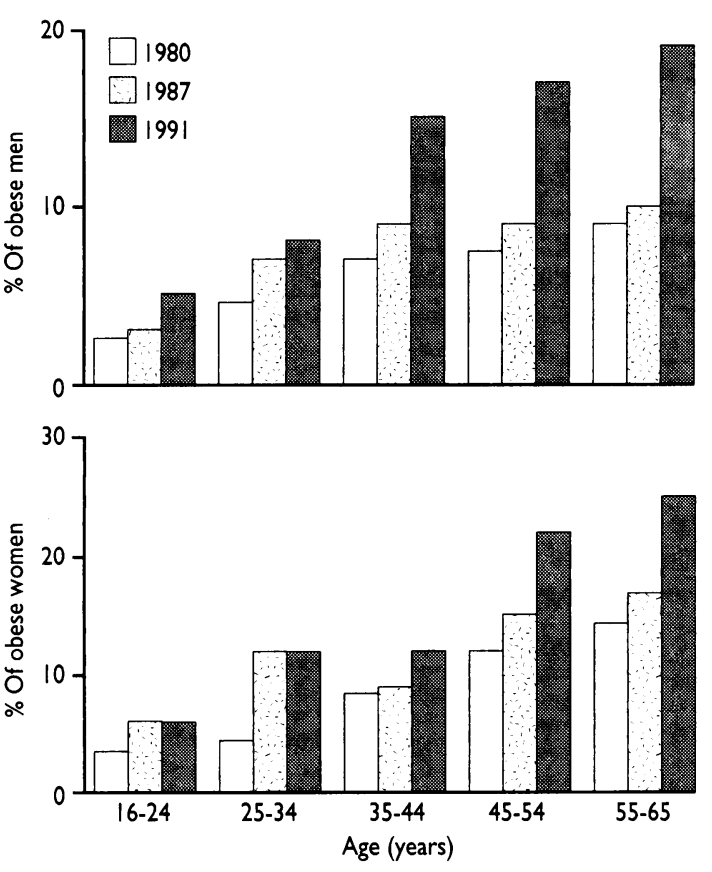

approach is required. Firstly, the Health Education Authority should publicise the level at which being overweight becomes a medical (rather than a cosmetic) problem: this occurs at a Quetelet's index of somewhere between 25 and 30 . Secondly, non-profit making but self financing slimming groups, led by state registered dietitians, should be set up as part of the health education service for overweight people. Such groups have been shown to be practicable and effective for the past 15 years in the Harrow health district. ${ }^{6}$ Thirdly, the group leader should be able to refer members of the group who present special problems to a hospital specialist for further investigation, advice, or treatment.

I have been running a hospital obesity clinic for more than 20 years: it operates inefficiently because most of the patients have not previously had proper dietary advice. If they had been filtered through a well run slimming group many would not have needed to come, and (for those who needed referral) time would have been saved by not having to start from scratch with dietary management. The objective is to lose $0.5-1.0 \mathrm{~kg} /$ week by a combination of restricted energy intake (dieting) and increased energy output (exercise) and to maintain the reduced weight indefinitely. Methods by which this may be achieved are discussed elsewhere.? Obesity is often treated badly. The solution is not to pretend it does not matter but to treat it well.

1 Garrow IS. Obesity and related diseases. London: Churchill Livingstone, 1988. 2 Garner DM, Wooley SC. Confronting the failure of behavioral and dietary treatments for obesity. Clin Psychol Rev 1991;11:729-80.

3 Bortz WM. A 500 pound weight loss. Am f Med 1969;47:325-31.

4 Garrow JS, Webster JD. Effects on weight and metabolic rate of obese women of a 3.4 MJ (800 kcal) diet. Lancet 1989;i:1429-31.

5 White A, Nicolaas G, Foster K, Browne F, Carey S. Health survey for England 1991. London: Office of Population Censuses and Surveys, 1993.

6 Bush A, Webster J, Chalmers G, Pearson M, Penfold P, Brereton P, et al. The Harrow slimming club: report on 1090 enrolments in 50 courses, 1977-1986. foumal of Human Nutrition and Dietetics 1988;1:429-36.

7 Garrow JS. Obesity. In: Garrow JS, James WPT, eds. Human nutrition and dietetics. 9th ed. Edinburgh. Churchill Livingstone, 1993:465-79.

\section{Dietary treatments for obesity are ineffective}

\section{Susan C Wooley, David M Garner}

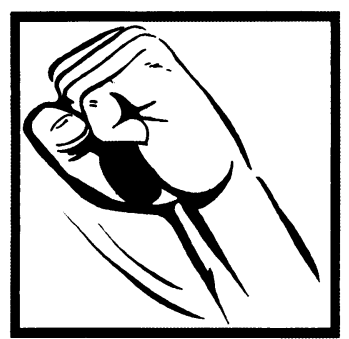

University of Cincinnati, College of Medicine, Cincinnati, Ohio 45267, USA

Susan C Wooley, professor of psychology

Beck Institute for Cognitive Therapy and Research, Bala Cynwood,

Pennsylvania 19001, USA

David M Garner, director of research

Correspondence to: Dr Wooley.
It is surprising that debate continues about the effectiveness of dietary treatments for obesity. Perhaps this is partly related to ambiguity in the term effectiveness. It is well known that most treatments produce temporary weight loss. But it is equally well known that $90 \%$ to $95 \%$ of those who lose weight regain it within several years. ${ }^{1}$ This poor outcome has led to charges that traditional treatments for obesity should be abandoned and countercharges that it is irresponsible to withhold treatment for such a serious problem. The failure of reducing diets to produce lasting improvement was recently reiterated at a National Institutes of Health consensus conference, which also warned about the adverse effects of treatment. ${ }^{2}$

The failure of fat people to achieve a goal they seem to want-and to want almost above all else-must now be admitted for what it is: a failure not of those people but of the methods of treatment that are used. It is no longer a mystery why diets have such a poor long term record of success. Indeed the failure of obese people to become or remain thin by "normalising" their food intake follows logically from studies on the heritability of obesity, ${ }^{3}$ the biology of weight regulation, ${ }^{4}$ and the physiology of energy metabolism. ${ }^{5}$

\section{Demand for treatment is not a justification}

Yet many remain enthusiastic about treatment. It could be said that the main evidence for the value of dieting is that health professionals continue to prescribe it. Inertia feeds on itself, failure to change coming to serve as a silent argument that no change is needed. However, this only partially accounts for the resistance to change among those treating obesity. Recent findings regarding the benefits of antibiotics in treating ulcers and the comparative outcomes of procedures for emergency cardiac care have been rapidly translated into medical practice. In these cases doctors have only had to adjust what they do; in the case of obesity treatment, however, there is no replacement procedure. The question is whether to abandon treatment, putting many specialists out of business, in the face of relentless popular demand. Desperate consumers are willing to bear the burden of responsibility for failure in exchange for continuing access to treatment. This desperation is best illustrated by Ravitch and Brolin's observation that patients who had had obesity surgery were unwilling to consider reversal even when it was discussed in terms of saving their lives. ${ }^{6}$

As if to avert the central question by introducing more variables, the debate has shifted from the universal mandate for one treatment, to the matching of available treatments (from self directed programmes to surgery) to individual, depending on level of obesity and factors such as diet history. ${ }^{7}$ Notably, even for patients as little as $5 \%$ overweight the option of withholding weight loss treatment does not appear on the decision tree. Wadden has argued that the "no treatment" option "cannot be universally endorsed until there are definitive research data." ${ }^{\circ}$ This is an unusual twist in medical science: demanding proof of effectiveness of no treatment rather than of active intervention. Although the no treatment stance has been viewed as radical, it is actually quite conservative. The drug industry has to show both safety and efficacy 